\title{
The Performance of Different Boundary-Layer Parameterisations in Meteorological Modelling in a Southwestern Coastal Area of the Iberian Peninsula
}

\author{
M. A. Hernández-Ceballos, ${ }^{1}$ J. A. Adame, ${ }^{2}$ J. P. Bolivar, ${ }^{1}$ and B. A. De la Morena ${ }^{2}$ \\ ${ }^{1}$ Department of Applied Physics, Faculty of Experimental Sciences, University of Huelva, 21071 Huelva, Spain \\ ${ }^{2}$ El Arenosillo Atmospheric Sounding Station, Atmospheric Research and Instrumentation Branch, \\ National Institute for Aerospace Technology (INTA), 21130 Huelva, Spain
}

Correspondence should be addressed to M. A. Hernández-Ceballos, miguelhceballos@gmail.com

Received 20 September 2012; Accepted 10 October 2012

Academic Editors: A. Cannon, A. Miranda, and P. Zanis

Copyright (C) 2012 M. A. Hernández-Ceballos et al. This is an open access article distributed under the Creative Commons Attribution License, which permits unrestricted use, distribution, and reproduction in any medium, provided the original work is properly cited.

\begin{abstract}
The performance of four atmospheric boundary layer $(\mathrm{ABL})$ schemes in reproducing the diurnal cycles of surface meteorological parameters as well as the ABL structure and depth over a coastal area of southwestern Iberia was assessed using the mesoscale meteorological Weather Research and Forecasting (WRF) model. The standard configuration of the medium-range forecast (MRF) and the Yonsei University (YSU) ABL schemes were employed. Modified versions of each, in which the values of the bulk critical Richardson number $\left(\mathrm{Rib}_{\mathrm{cr}}\right)$ and the coefficient of proportionality $(b)$ were varied, were also used. The results were compared to meteorological measurements representative of SW-NW and NE synoptic flows. The WRF model in its basic configuration was found to yield satisfactory forecasting results for nearly all near-surface atmospheric variables. Modifications in Rib $\mathrm{cr}_{\mathrm{cr}}$ and $b$ did not influence the simulation of surface meteorological parameters. Both parameterisations appeared to be optimal predictors of $\mathrm{ABL}$ structure, and all four ABL schemes tended to produce a cold ABL during both periods, although this ABL was drier in the SW-NW flow season and wetter in the NE flow season. Considering all the parameters analysed, the MRF ABL parameterisation with the lowest values of $\mathrm{Rib}_{\mathrm{cr}}$ and $b$ coefficients tested ( 0.25 and 0.0 , resp.) tends to show a realistic simulation.
\end{abstract}

\section{Introduction}

The atmospheric boundary layer $(\mathrm{ABL})$ is the part of the troposphere that is directly influenced by the presence of the Earth's surface, responding to changes in surface parameters within a time scale of one hour or less [1]. Physical parameters such as flow velocity, temperature, and moisture exhibit rapid fluctuation in this layer as a result of transport processes (turbulence) generated by the warming and cooling of the ground in response to solar radiation. These fluctuations manifest in the diurnal variation in the ABL as well as in the temporal and spatial variation in the thickness of this layer, which ranges from hundreds of meters to a few kilometres.

Due to the importance of the ABL for the biosphere, including human life, the structure and temporal evolution of this layer has been a focus of environmental studies $[2,3]$.
Vertical profiles of mean wind velocity and the turbulent vertical exchange of momentum, heat, and moisture [4] have been widely analysed because these parameters affect nearsurface pollutant concentrations.

A classical approach to understanding ABL characteristics involves the use of experimental data obtained from meteorological soundings $[5,6]$. Unfortunately, these observations are restricted to stations at which launches occur frequently, that is, these data provide limited spatial and temporal coverage. Therefore, it is desirable to develop a parameterisation that enables accurate modelling of ABL features at any location and for any time period.

The high-resolution Weather Prediction System (WPS) meteorological models are widely used in studies of the ABL. In these models, several possible $\mathrm{ABL}$ parameterisations have been implemented as a result of the progressive increase in the ability of researchers to produce an accurate description 
of the ABL. One example is the Yonsei University (YSU) scheme [7], which is based on a nonlocal- $K$ scheme with an explicit entrainment layer and a parabolic $K$ profile in an unstable mixed layer. Another example is the MellorYamada-Janjic scheme [8], which is characterised by a onedimensional prognostic turbulent kinetic energy scheme with local vertical mixing. The medium-range forecast (MRF) [9] scheme, which is an older version of the YSU scheme, is characterised by implicit treatment of the entrainment layer as part of a nonlocal- $K$ mixed layer.

Considering this wide range of parameterisations, several studies have examined the reliability of different $\mathrm{ABL}$ schemes for various locations and meteorological scenarios. Wisse and Vilà-Guerau de Arellano [10] studied the accuracy of several ABL schemes (MRF, BLA, and Eta-Mellor-Yamada (ETA)) in predicting the development and evolution of a severe convective storm. Dandou et al. [11] correlated the mixing heights obtained from ceilometer and Sodar measurements with those simulated by the MRF, BLA, Gayno-Seaman, Pleim-Xiu, and MRF-urban schemes for two sites near Munich on two days in spring and winter.

The southwestern Iberian Peninsula is a suitable region for the investigation of environmental problems involving secondary chemical species $[16,17]$, due to a combination of several factors. Both biogenic and anthropogenic sources of atmospheric emissions exist in the region (the anthropogenic sources include metropolitan areas with high population densities and industrial zones). In addition, the complex orography (the Guadalquivir valley) and the meteorological conditions (high temperatures and solar radiation levels) of the region favour high air pollutant levels during certain periods. Improved knowledge of $\mathrm{ABL}$ behaviour in this region will help to improve the understanding of these atmospheric problems. The authors in [18] studied the interactions between atmospheric boundary layer (ABL) dynamics and atmospheric chemistry using a mixed-layer model coupled to chemical reaction schemes, guided by both atmospheric and chemical measurements obtained during the DOMINO (Diel Oxidant Mechanisms in relation to Nitrogen Oxides) campaign (2008).

The aim of the present study is to evaluate the performance of four different schemes in the characterisation of the ABL under two common meteorological scenarios in coastal southwestern Iberia: the arrival of SW-NW and NE synoptic flows. To achieve this objective, the predictions of the standard configurations of the MRF and YSU schemes, which have already been incorporated into the Weather Research and Forecasting (WRF) model, and modified versions of each of these based on variations in the values of the bulk critical Richardson number ( $\mathrm{Rib}_{\mathrm{cr}}$ ) and the coefficient of proportionality $(b)$, were compared with surface and profile observations from the coastal site of El Arenosillo in southwestern Spain.

\section{Observations and Modelling Setup}

The area features as well as the characteristics of the meteorological conditions during the analysed periods are presented in the first point of this section, followed by the description and setup configuration of the WRF-ARW model as well as the ABL parameterizations used in this study in the second one. Finally, the methodology employed to perform this comparison is explained.

2.1. Observation Site, Measurements, and Meteorological Conditions. Meteorological observations were obtained at El Arenosillo-Atmospheric Sounding Station (37.1 N, 6.7 W), which belongs to the National Institute for Aerospace Technology (INTA) (Figure 1(a)). El Arenosillo station is devoted to atmospheric observation and related research in areas such as meteorology, air pollution, and radiation. It is located on the southwest coast of the Iberian Peninsula, at the edge of the European continent. The observatory is located approximately to $1 \mathrm{~km}$ of the coastline (Figure 1(b)) and is surrounded by a natural environment characterised by a uniform cover of pines (mainly Stone Pines, Pinus pinea, which are typically $5-10 \mathrm{~m}$ in height) and dry soils. The relatively flat orography of the site and its distance from industrial activities as well as its facilities and the availability of a large meteorological database make of this station a strategic location for meteorological studies.

Two periods of 3 days were selected in order to investigate ABL behaviour during two of the most common meteorological scenarios in the region [19]. The first period comprised 27-29 April 2008, which was representative of an intensive arrival of SW-NW winds. The second period covered 22-24 November 2008, in which NE flows were dominant over the area.

To determine the behaviour of the ABL, data from three meteorological soundings, one performed on each of the three consecutive days, were used. These data included profiles of wind speed and direction, temperature, relative humidity, and pressure from the surface to a height of approximately $20-25 \mathrm{~km}$. In addition, the hourly surface values of the same meteorological parameters were measured at an elevation of $10 \mathrm{~m}$ above ground level (agl).

2.2. WRF Model and ABL Parameterizations. The Weather Research and Forecasting (WRF) model was used in this study. This model is a next-generation mesoscale model designed for several applications including research, operational regional weather forecasting, data assimilation, parameterised-physics research, driving air quality models, atmosphere-ocean coupling, and idealised simulations. The WRF model has been developed with multiple dynamic cores to support both research and operational applications. The specific version used in this study is the Advanced Research version of the WRF (ARW), which is based on an Eulerian mass dynamical core [20]. The WRF-ARW model has multiple physics options for microphysics as well as cumulus cloud, surface, planetary boundary layer, and atmospheric radiation physics.

The WRF-ARW model consists of fully compressible nonhydrostatic equations, and its prognostic variables include the three-dimensional wind flow, potential temperature perturbations, geopotential, surface pressure, turbulent 


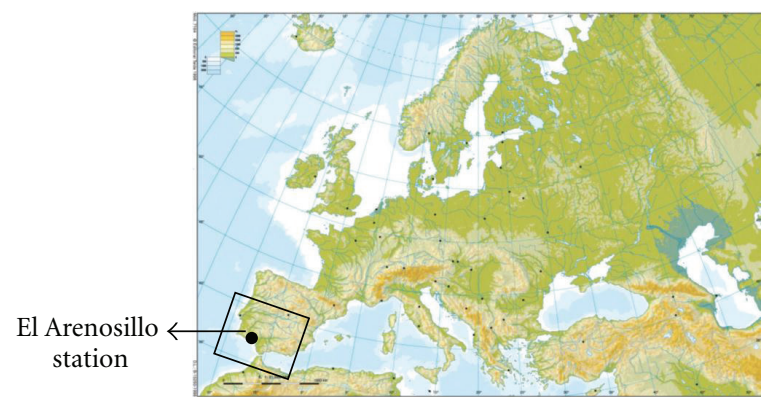

(a)

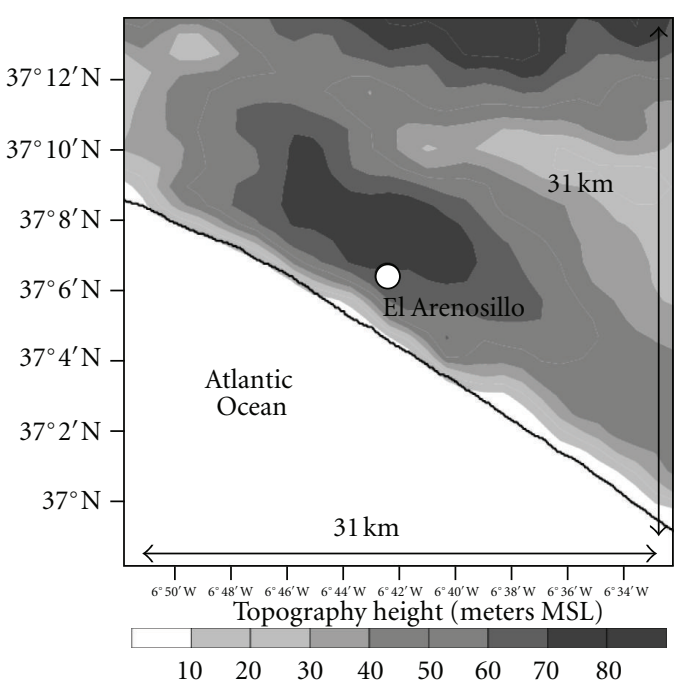

(b)

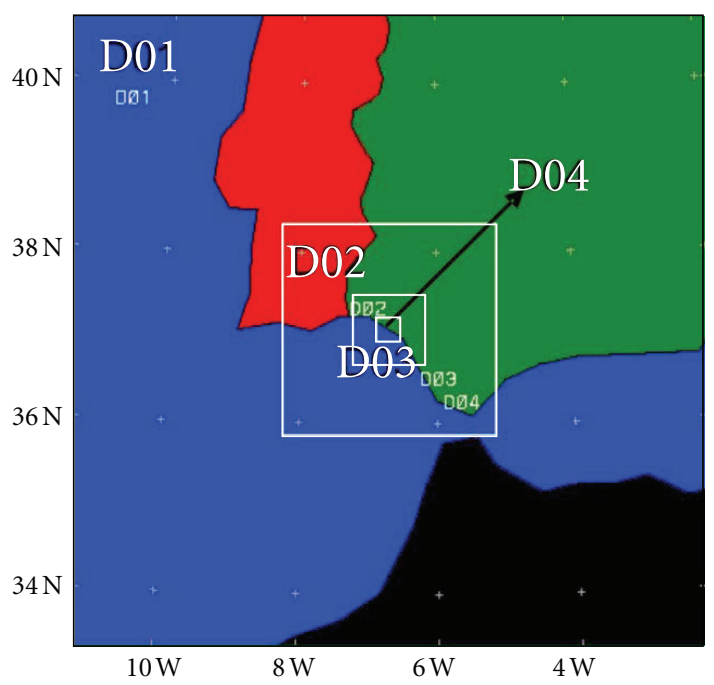

(c)

Figure 1: (a) Location of El Arenosillo station in southwestern Europe. (b) The topography of the inner domain with contour lines at $10 \mathrm{~m}$ intervals. (c) The nest configuration of the four research domains (Lambert conformal projection).

kinetic energy, and scalars (water vapour mixing ratio, cloud water, etc.). The solver uses a second- or third-order RungeKutta time integration scheme with a small time step for the acoustic and gravity-wave modes. Second- to sixth-order advection options are used in the horizontal and vertical spatial discretisation. The vertical coordinate of the model is terrain-following hydrostatic pressure (the eta coordinate) and the horizontal grid is the staggered Arakawa C-grid.

The initial and lateral boundary conditions for the outermost domain were obtained from 6-hourly global analyses supplied by the European Centre for MediumRange Weather Forecast (ECMWF) numerical prediction model with a spatial resolution of $0.25^{\circ} \times 0.25^{\circ}$ (longitude $\times$ latitude) and 17 vertical pressure levels. Topographic information was obtained from the US Geological Survey (USGS) global 30 arc-s elevation (GTOPO30) dataset [21], which allowed optimal topographical representation of the study area (Figure 1(b)). In addition, the USGS land use/land cover system was used to classify the physical properties of the surface [22].

Four domains centred at El Arenosillo station were defined (Figure 1(c)). Each domain has the dimensions of a $31 \times 31$ grid, with the grid cell size decreasing from $27 \mathrm{~km}$ to $1 \mathrm{~km}$ (ratio of 3 ) from the largest to the smallest domain. This configuration allowed the study of ABL behaviour in the inner domain at a spatial resolution of $1 \mathrm{~km}$. The WRF model was built over a mother domain (D1) at a spatial resolution of $27 \mathrm{~km}$. This domain covered the southwestern Iberian Peninsula, the western end of the Mediterranean Sea, and a small area of northern Africa. The first nested domain (D2) had a spatial resolution of $9 \mathrm{~km}$ and covered the Strait of Gibraltar, southwestern Spain, and southeastern Portugal. The third domain (D3), with a resolution of $3 \mathrm{~km}$, was situated over the southern Huelva region, and the 
TABLE 1: Details of the physics options used in the WRF model.

\begin{tabular}{ll}
\hline $\begin{array}{l}\text { Domains } \\
\text { Dynamics }\end{array}$ & $\begin{array}{l}\text { Four nested domains (domains } 1-4) . \\
\text { Primitive equation, nonhydrostatic. } \\
\text { Radiation }\end{array}$ \\
$\begin{array}{l}\text { [12] scheme for short wave radiation, rapid } \\
\text { radiative transfer model (RRTM) for long } \\
\text { wave radiation. }\end{array}$ \\
$\begin{array}{l}\text { 5-layer soil diffusion scheme }[13] . \\
\text { Boundary layer } \\
\text { MRF-St }\left(\mathrm{Ri}_{\mathrm{cr}}=0.5 ; b=7.8\right), \mathrm{YSU}-\mathrm{St} \\
\left(\mathrm{Ri}_{\mathrm{cr}}=0.5 ; b=7.8\right), \mathrm{MRF}-\mathrm{Mod}\left(\mathrm{Ri}_{\mathrm{cr}}=0.25 ;\right. \\
\begin{array}{l}\text { Cumulus } \\
\text { Sea surface } \\
\text { temperature }\end{array}\end{array}$ & $\begin{array}{l}\mathrm{A} \text { modified version of }[14,15] . \\
\text { ECMWF analysis data. }\end{array}$ \\
\hline
\end{tabular}

finest-scale domain (D4) covered the $31 \mathrm{~km}^{2}$ area surrounding El Arenosillo observatory site.

A two-way interactive nested technique was used to run the high-resolution simulation. The vertical levels were divided into 40 sigma $(\sigma)$ layers from bottom to top, where $\sigma$ is defined as $\sigma=\left(p-p_{0}\right) /\left(p_{\text {sfc }}-p_{\text {top }}\right)$. Here, $p$ represents pressure, $p_{0}$ is the reference surface pressure, and $p_{\text {sfc }}$ and $p_{\text {top }}$ are the pressures at the surface and in the top layer, respectively. A denser region of sigma levels in the lower atmosphere ( $27 \sigma$ up to $2000 \mathrm{~m}$ ) was generated, which enables optimal resolution of the ABL behaviour. Table 1 shows the set of physics options used in the numerical simulations by the WRF model.

The above-mentioned model features were identical for all of the sensitivity experiments, but the ABL parameterisation schemes differed across simulations. Two standard ABL parameterisations implemented in the WRF model were tested: the high-resolution nonlocal MRF (MRF) scheme and the Yonsei University (YSU) scheme. The YSU scheme is an updated and improved version of the MRF scheme [7, 9].

The major difference between the MRF and YSU schemes is that the YSU scheme includes an explicit treatment of entrainment processes at the top of the ABL whereas entrainment is implicitly parameterised in the MRF scheme. The YSU scheme incorporates nonlocal momentum transport (for daytime) while the MRF scheme incorporates only local mixing. In addition, the two schemes use different definitions to determine ABL height $(h)$ internally. In the MRF scheme, the top of the $\mathrm{ABL}$ is defined as the level of the minimum flux within the inversion level, which is described as an implicit function of the bulk Richardson number, the horizontal wind speed, and the virtual potential temperature. This function also approximates the growth of the daytime mixed layer and allows treatment of cases in which surface heat flux is weak as well as transitions between stable and unstable cases. The latter is achieved by relating the appropriate temperature near the surface to the temperature of thermals via the standard "countergradient" flux correction for the unstable case [23].

In contrast, in the YSU (Yonsei University) scheme, ABL height is defined based on the bulk Richardson number by a process of integration. In this scheme, ABL height corresponds to the critical bulk Richardson number and is obtained by linear interpolation between the two adjacent model levels. The critical bulk Richardson number $\left(\mathrm{Rib}_{\mathrm{cr}}\right)$ is set at 0.5 , and a revised nonlocal vertical diffusion scheme is applied in the model.

Because the different schemes define ABL height differently, one cannot judge the model performance for $h$ directly. Of the existing methods to determine ABL depth (e.g., bulk Richardson number, potential temperature profile, and eddy viscosity), the present study used the vertical profile of potential temperature $(\theta)$ [24]. In particular, the top of the mixing layer was assumed to be the lowest inversion at which the potential temperature lapse rate is at a maximum. This method was used because the vertical resolution defined in this study (40 sigma levels) was sufficient to resolve ABL structure in detail and because of its validity in showing well-defined capping inversion under daytime convective conditions. Vogelezang and Holtslag [25] noted that the use of $\mathrm{Rib}_{\text {cr }}$ to compute ABL height generally yields accurate values over land but may result in high $\mathrm{ABL}$ height over water in high winds.

In both ABL schemes, the bulk critical Richardson number and the coefficient of proportionality $(b)$ contribute to the determination of ABL height and thermal and humidity properties. The value of $\mathrm{Rib}_{\mathrm{cr}}$ determines the height at which continuous turbulence vanishes (considering both thermal and mechanical sources of turbulence), and the height at which the Richardson number $\left(\mathrm{Ri}_{b}\right)$ reaches $\mathrm{Rib}_{\mathrm{cr}}$ is taken as ABL height [26]. The $b$ coefficient contributes to the computation of the countergradient term [27] and the scaled virtual temperature excess near the surface, which determine the value calculated for the temperature near the surface [9]. The default values of these coefficients are $\mathrm{Rib}_{\mathrm{cr}}=0.5$ and $b=0.0$ in both the MRF and YSU schemes.

Considering the relevance of Rib $\mathrm{cr}_{\mathrm{cr}}$ and $b$ in the determination of ABL height in both schemes, the sensitivity of the WRF model to changes in these two parameters was investigated here. Taking into account the results of the authors in [9], who found that increases in $\mathrm{Rib}_{\mathrm{cr}}$ and $b$ had very little impact on $A B L$ structure, the four $A B L$ schemes compared in this study were (1) MRF-St ( $\operatorname{Rib}_{\mathrm{cr}}=0.5 ; b=$ 7.8 ), (2) YSU-St $\left(\mathrm{Rib}_{\mathrm{cr}}=0.5 ; b=7.8\right)$, (3) MRF-Mod $\left(\operatorname{Rib}_{\mathrm{cr}}=0.25 ; b=0.0\right)$, and (4) YSU-Mod $\left(\operatorname{Rib}_{\mathrm{cr}}=0.25 ; b=\right.$ $0.0)$.

2.3. Methodology. To determine the performance of each model configuration in the analysis of weather conditions for each scenario, the meteorological surface values and vertical profiles simulated for the inner domain were compared with empirical data collected at El Arenosillo. Diurnal variation in the $\mathrm{ABL}$ depths obtained using each WRF configuration was also analysed.

To assess the accuracy of each prediction, the root mean square error (RMSE) between the forecast and observed values of each surface variable (wind speed, potential temperature, and specific humidity) was calculated. The bias score (BIAS), which measures the tendency of a model to systematically overestimate or underestimate a parameter, 


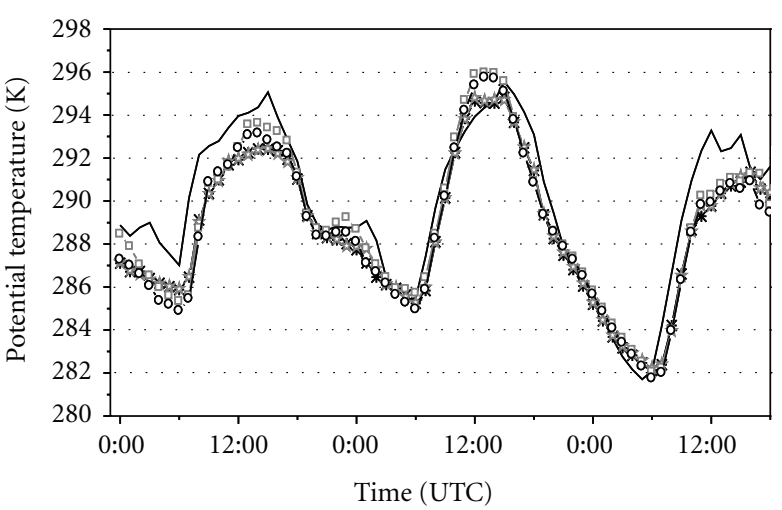

(a)

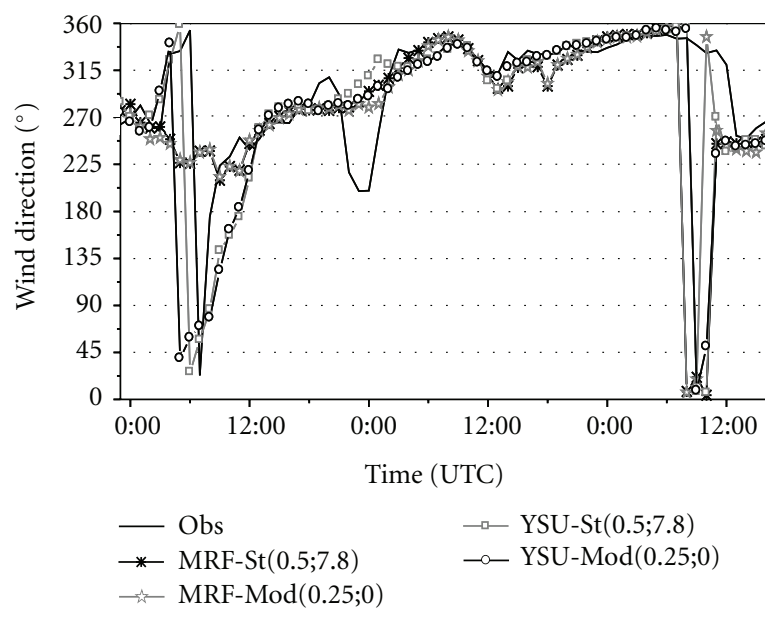

(c)

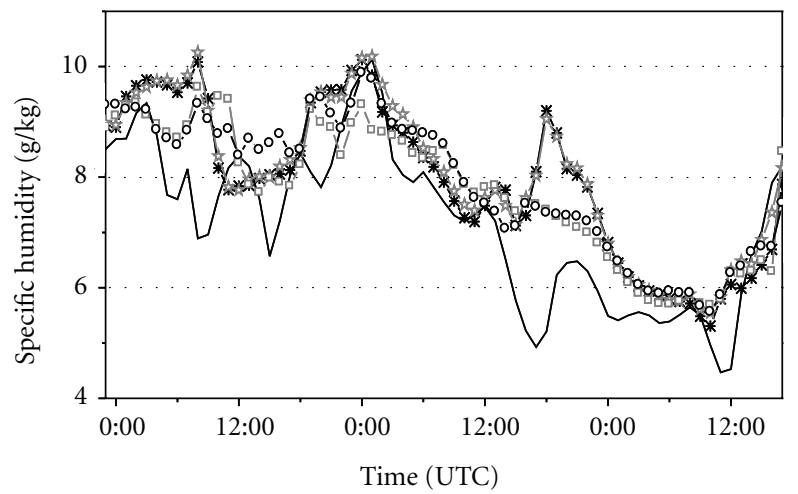

(b)

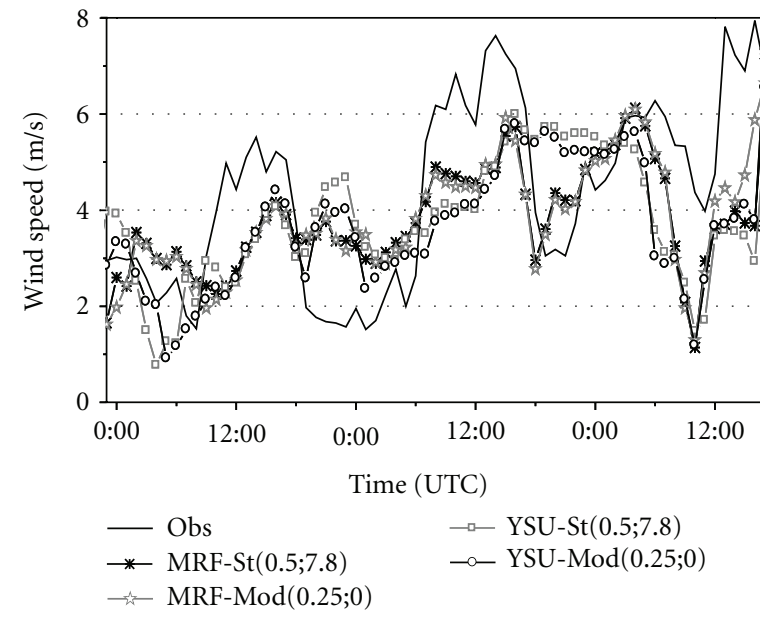

(d)

FIGURe 2: Hourly evolution of observations (solid lines) and simulations (lines + symbols) using four ABL schemes (MRF-St, MRF-Mod, YSU-St, and YSU-Mod) of (a) potential temperature, (b) specific humidity, (c) wind direction, and (d) wind speed in the D4 domain from 27 April 2008 at 00:00 UTC to 29 April 2008 at 18:00 UTC.

was also calculated. To analyse the performance of each ABL scheme with regard to wind direction, the minimum angular distance of wind direction was calculated using the criteria described in [28].

A simulation of 3 days (72 hours) was performed for each scenario. In each case, the preceding 24 hours were treated as spin-up time to accommodate the increases in grid length and the adjustment of the $\mathrm{ABL}$ processes to the different ABL parameters as well as to avoid problems related to the adjustment of the large-scale flow according to the local topography, land use, and other factors.

\section{Results}

This section presents the results obtained in this work corresponding to the SW-NW and NE synoptic scenarios over southwestern Iberian Peninsula. In each point, we present the observations and the modelling results of surface (wind speed and direction, potential temperature, and specific humidity) and vertical profiles, as well as the statistical comparison performed.
3.1. Case 1: SW-NW Synoptic Flow (27-29 April 2008). The scenario of synoptic flow from the SW or the NW is common in this region. This scenario is associated with the influence of high- or low-pressure centres located over the Atlantic Ocean (SW flows) or to the north of Iberian Peninsula (NW flows). At the beginning of the selected period, on 27 April 2008 , the synoptic conditions were governed by the presence of a high-pressure system to the west of the Iberian Peninsula, which was progressively modified in its influence over this area by the southward movement from high latitudes of a low-pressure system on 28 April. At the end of the 3-day period, on 29 April, this low-pressure system had reached the northern Iberian Peninsula and was the dominant influence on the local meteorological conditions.

The hourly evolution of the observed surface meteorological conditions and the simulations of the four $\mathrm{ABL}$ schemes for the inner domain under these synoptic conditions are shown in Figure 2. Table 2 gives the RMSE and BIAS results obtained for the comparison of these observations and simulations.

The observed wind direction changed from $\mathrm{W}$ to NW over the 3-day period, and the daily maximum wind speed 
TABLE 2: Bias score (BIAS) and root mean square error (RMSE) values obtained in comparisons of observed values and the values predicted by four ABL schemes for wind speed (WS), potential temperature $\left(T_{p}\right)$, and specific humidity $(q)$ for the period from 27 April 2008 at $00: 00$ UTC to 29 April 2008 at 18:00 UTC.

\begin{tabular}{lccccccc}
\hline & \multicolumn{2}{c}{ MRF-St } & \multicolumn{2}{c}{ MRF-Mod } & \multicolumn{2}{c}{ YSU-St } & \multicolumn{2}{c}{ YSU-Mod } \\
& RMSE & BIAS & RMSE & BIAS & RMSE & BIAS & RMSE \\
\hline WS $\left(\mathrm{m} \mathrm{s}^{-1}\right)$ & 1.66 & -0.51 & 1.56 & -0.52 & 2.02 & -0.62 & 1.89 \\
$T_{p}(\mathrm{~K})$ & 1.59 & -1.20 & 1.56 & -1.14 & 1.52 & -0.80 & -0.70 \\
$q\left(\mathrm{~g} \mathrm{~kg}^{-1}\right)$ & 1.26 & 0.80 & 1.28 & 0.91 & 1.03 & 0.61 & 1.70 \\
\hline
\end{tabular}

increased from 6 to $8 \mathrm{~m} \mathrm{~s}^{-1}$. The potential temperature ranged from 295 to $282 \mathrm{~K}$, with a significance level of a clear daily cycle, and the specific humidity exhibited a decreasing trend within a range of $10-5 \mathrm{~g} \mathrm{~kg}^{-1}$. The mean values, with a significance level of $95 \%$, were $4.4 \pm 0.4 \mathrm{~m} \mathrm{~s}^{-1}, 289.8 \pm 0.8 \mathrm{~K}$, and $7.1 \pm 0.3 \mathrm{~g} \mathrm{~kg}^{-1}$, respectively.

Regarding the simulations, in the case of wind direction, all four schemes accurately reproduced the observed temporal evolution. As mentioned in Section 2.3, the minimum angular distance was calculated, and this was found to range from $-45^{\circ}$ to $45^{\circ}$. The observed wind speed tended to be underestimated by the simulations during the daytime and overestimated at night, with high similarity between the two MRF schemes (MRF-St and MRF-Mod) and between the two YSU schemes (YSU-St and YSU-Mod). The statistical parameters tended to predict low values for wind speed (negative BIAS), but, remarkably, the RMSE values were lower for the modified schemes in this case. The mean values of wind speed, with a significance level of $95 \%$, were $3.9 \pm 0.3 \mathrm{~m} \mathrm{~s}^{-1}$ for MRF_St, $3.9 \pm 0.3 \mathrm{~m} \mathrm{~s}^{-1}$ for MRF_Mod, $4.0 \pm 0.3 \mathrm{~m} \mathrm{~s}^{-1}$ for YSU_St, and $3.7 \pm 0.3 \mathrm{~m} \mathrm{~s}^{-1}$ for YSU_Mod, respectively.

All four schemes accurately reproduced the daily patterns of potential temperature but tended to underestimate the observed values (negative BIAS) by $0.80-1.20 \mathrm{~K}$. The highest differences between the observed and predicted values occurred for the maximum daily potential temperature. Here, the results of the YSU schemes were nearly $1 \mathrm{~K}$ higher than those of the MRF schemes. The mean values of potential temperature, with a significance level of $95 \%$, were $288.6 \pm$ 0.8 K for MRF_St, 290.1 $\pm 0.8 \mathrm{~K}$ for MRF_Mod, $290.2 \pm 0.8 \mathrm{~K}$ for YSU_St, and $288.7 \pm 0.8 \mathrm{~K}$ for YSU_Mod, respectively. The simulated specific humidity values exhibited the decreasing trend that was observed in the empirical data, and similar evolutions were registered by the YSU and MRF schemes, but the differences between the predicted and the observed values were higher for this parameter than for potential temperature. In this case, the YSU schemes yielded lower RMSE values than did the MRF schemes, and the BIAS values indicated a general overestimation in the range of 0.61 to $0.91 \mathrm{~g} \mathrm{~kg}^{-1}$. The mean values of specific humidity, with a significance level of $95 \%$, were $7.9 \pm 0.3 \mathrm{~g} \mathrm{~kg}^{-1}$ for MRF_St, $8.0 \pm 0.3 \mathrm{~g} \mathrm{~kg}^{-1}$ for MRF_Mod, $7.9 \pm 0.3 \mathrm{~g} \mathrm{~kg}^{-1}$ for YSU_St, and $7.9 \pm 0.3 \mathrm{~g} \mathrm{~kg}^{-1}$ for YSU_Mod, respectively.

The vertical profiles of simulated potential temperature and specific humidity for the fine grid domain (D4) were compared with data from soundings performed on 27 April 2008 at 11:00 UTC and on each of the subsequent two days at 12:00 UTC (Figure 3). The observed temperature and humidity profiles were accurately simulated by all four schemes during stable morning conditions on 27 April, and the similarity in the profiles obtained for this time point by each of the ABL schemes was high (Figure 3(a)). Temperature was generally underestimated by 2 to $4 \mathrm{~K}$, and humidity was underestimated by $2-2.5 \mathrm{~g} \mathrm{~kg}^{-1}$ up to $600 \mathrm{~m}$ agl and by lower amounts above this elevation. Greater differences among ABL schemes were observed in the profiles simulated for 28 April (Figure 3(b)). In this case, the sounding data indicated a well-defined mixing boundary layer at a height of $500 \mathrm{magl}$, which was clearly overestimated by all ABL schemes. The schemes varied in their determination of ABL height, with the highest value generated by the YSU-St scheme. However, all four ABL schemes accurately represented both temperature (minimal underestimation) and humidity (underestimation of less than $0.5 \mathrm{~g} \mathrm{~kg}^{-1}$ ) profiles in the convective layer for this time point.

The empirical data for 29th April (Figure 3(c)) showed a well-defined mixed boundary layer reaching a height of nearly $1200 \mathrm{~m}$ agl. The simulated results predicted a shallower, unstable layer. The differences between the predicted and observed potential temperature profiles for this time point were relatively high (underestimation of $2-3 \mathrm{~K}$ ). The differences between the predicted and observed humidity profiles in the convective layer were not as high.

The hourly evolution of the ABL height over the 3day period as derived using each $\mathrm{ABL}$ scheme is shown in Figure 3(d). The potential temperature gradient was used to obtain the ABL heights for both the simulations and the empirical data. Over the 3-day period, the simulated daytime mixing layer depths were widely spread, reflecting differences across schemes in the representation of the depth of turbulence associated with the mixing height. In contrast, the simulated night time mixing layer depths were similar across schemes. Within a trend of increasing mixing height over the 3-day period, the YSU scheme tended to yield the highest values. This scheme also tended to forecast low ABL heights for nighttime or early morning hours. The maximum mixing layer heights obtained in simulations using the YSUSt scheme were $\sim 800 \mathrm{~m}$ agl on 27 April, $\sim 1400 \mathrm{~m}$ agl on 28 April, and $\sim 1800 \mathrm{~m}$ agl on 29 April. The minimum values were obtained using the MRF-Mod scheme, which yielded values from 300 to $1600 \mathrm{~m}$ agl. The ABL depths calculated using the MRF-St scheme were close to those calculated using the YSU-Mod scheme, and both of these schemes generated intermediate values.

The mixing layer heights obtained in the simulations were similar to the observed values, with maximum 

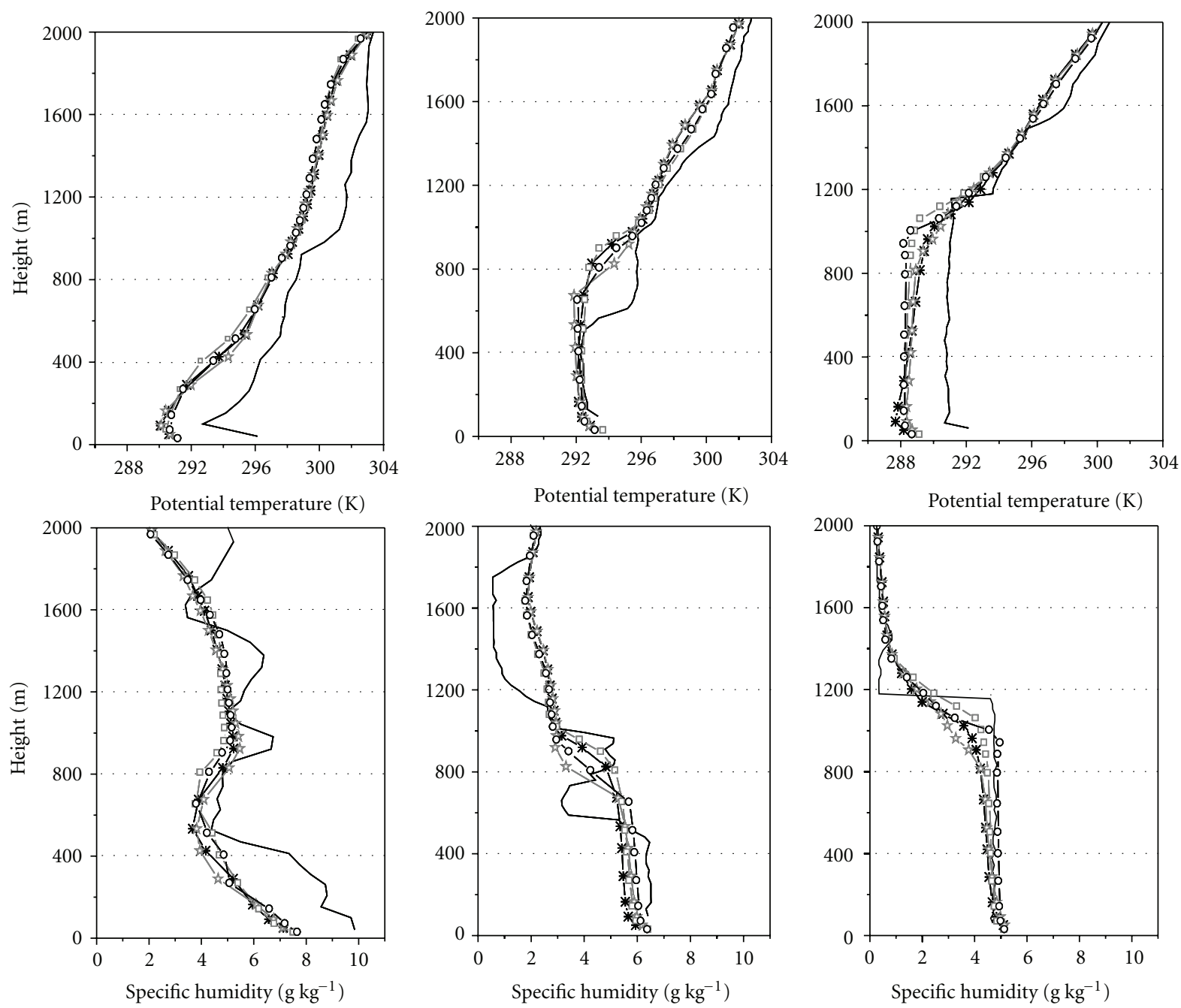

(a) $27 / 04 / 2011$ 11:00 UTC

(b) 28/04/2011 12:00 UTC

(c) $29 / 04 / 2011$ 12:00 UTC

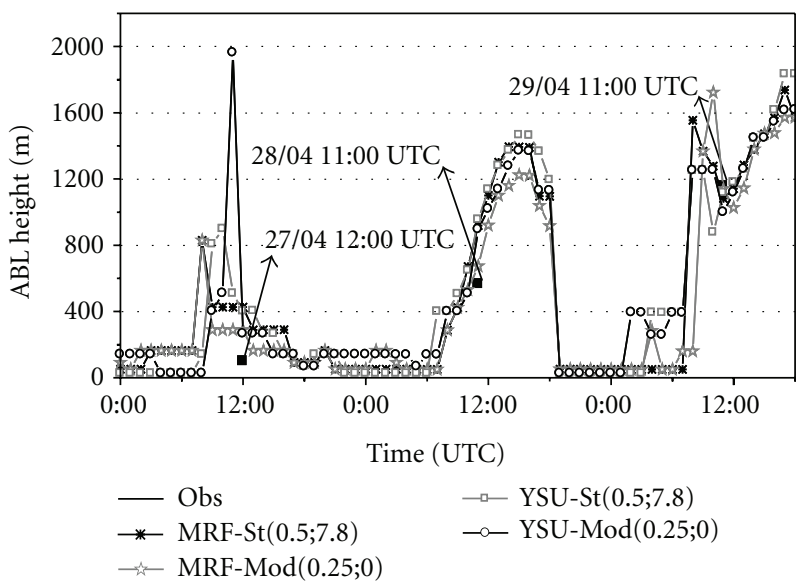

(d)

FIGURE 3: Observations (solid lines) and simulations (lines + symbols) using the MRF-St, MRF-Mod, YSU-St, and YSU-Mod schemes for vertical profiles of potential temperature and specific humidity for (a) 11:00 UTC on 27 April 2008, (b) 12:00 UTC on 28 April 2008, and (c) 12:00 UTC on 29 April 2008. (d) Hourly evolution of the mixing layer height obtained from the simulations (lines + symbols) and from meteorological soundings (black points) for the period from 27 April 2008 at 00:00 UTC to 29 April 2008 at 18:00 UTC. 


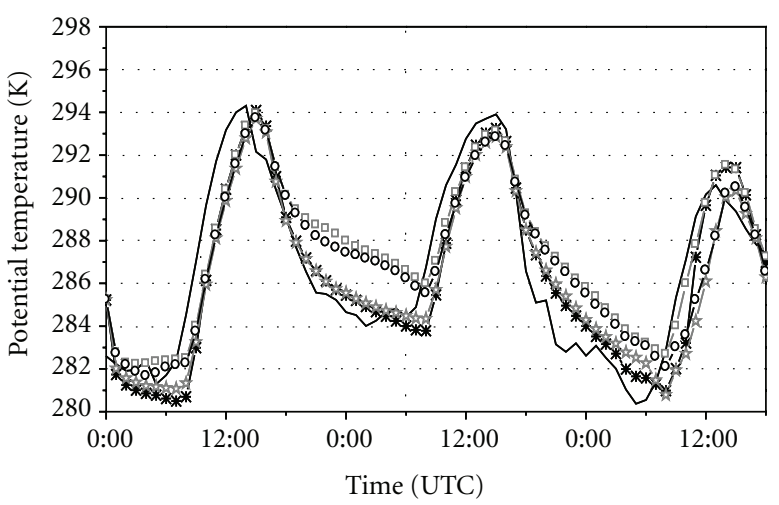

(a)

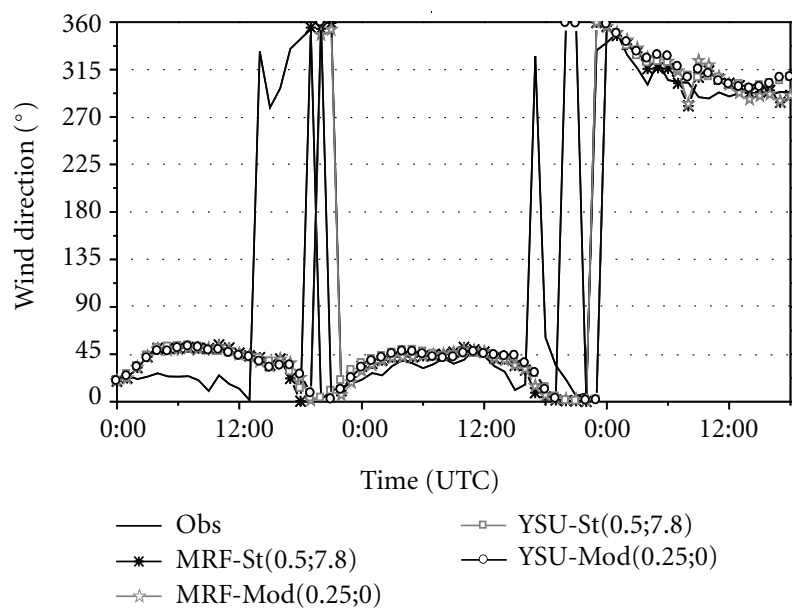

(c)

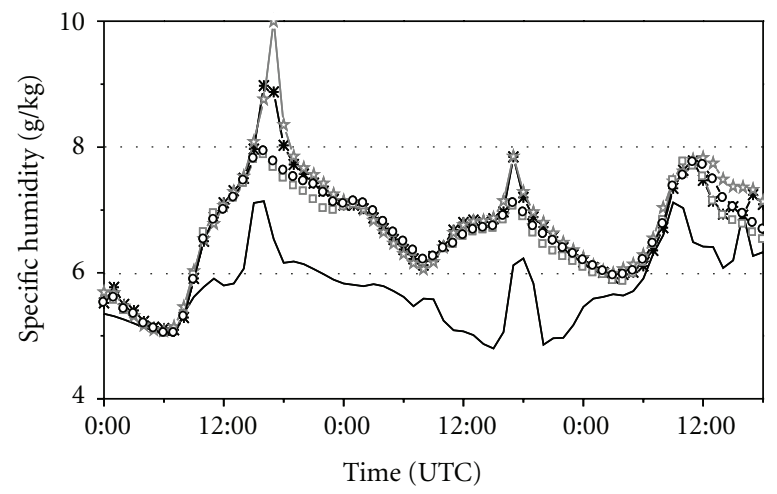

(b)

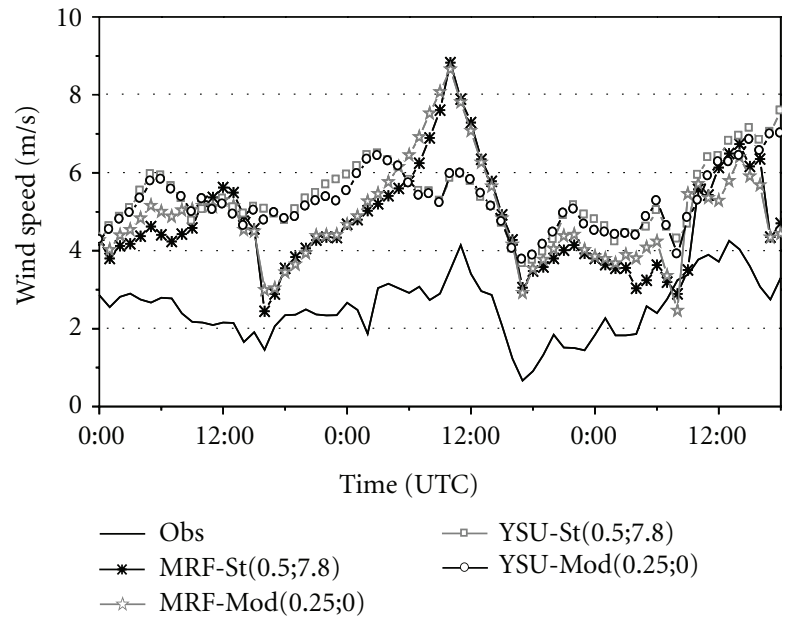

(d)

FIGURE 4: Hourly evolution of observations (solid lines) and simulations (lines + symbols) using four ABL schemes (MRF-St, MRF-Mod, YSU-St, and YSU-Mod) of (a) potential temperature, (b) specific humidity, (c) wind direction, and (d) wind speed in the D4 domain from 22 November 2008 at 00:00 UTC to 24 November 2008 at 18:00 UTC.

differences of approximately $200 \mathrm{~m}$. An overestimation of the ABL depth by the simulations was observed for the first two soundings, whereas better results were obtained for the third day. The results that agreed most closely with the observations were obtained using the MRF-Mod scheme.

3.2. Case 2: NE Synoptic Flow (22-24 November 2008). The arrival of NE flows in the study area is conditioned by the orographic characteristics of the region, specifically, the channelling effect that the Guadalquivir valley exerts on northerly winds. In the 3-day period from 22-24 November 2008, the synoptic conditions were characterised by an isobaric configuration with high- and low-pressure systems to the west and the east of the Iberian Peninsula, respectively. A progressive westward movement of the low-pressure system was observed on 24 November, which increased the influence of this system over the Iberian Peninsula.

Under these synoptic conditions, NE flows were recorded during the first two days with occasional changes in wind direction toward the northwest and a constant wind speed of approximately 2-3 $\mathrm{m} \mathrm{s}^{-1}$ (Figure 4). On the third day, a change in the prevailing wind occurred with the arrival of a northwestern flow at a speed closer to $4 \mathrm{~m} \mathrm{~s}^{-1}$. Both the potential temperature and the specific humidity were characterised by well-defined cycles. The maximum value of temperature decreased on 24 November from 294 K to 290 K, and the specific humidity ranged between 3 and $7 \mathrm{~g} \mathrm{~kg}^{-1}$. The mean values, with a significance level of $95 \%$, were $2.6 \pm 0.2 \mathrm{~m} \mathrm{~s}^{-1}, 286.5 \pm 0.9 \mathrm{~K}$, and $5.8 \pm 0.1 \mathrm{~g} \mathrm{~kg}^{-1}$, respectively.

A comparison between these meteorological observations and the results simulated using each of the four $\mathrm{ABL}$ schemes for this 3-day period are shown in Figure 4. Table 3 lists the statistical results (RMSE and BIAS values) for the inner modelling domain.

All of the simulated results correctly represented the observed variation in wind direction. No large differences among the simulated results were observed, and, in general, only a short delay was observed in the simulations of the abrupt changes in wind direction. The minimal angular distance ranged from $20^{\circ}$ to $-45^{\circ}$. For the same period, the wind speeds predicted by the simulations were systematically higher than the observed wind speeds (positive BIAS of 2.25$2.85 \mathrm{~m} \mathrm{~s}^{-1}$ ), regardless of which ABL parameterisations were used. The patterns of temporal evolution in wind speed 
TABLE 3: Bias score (BIAS) and root mean square error (RMSE) values obtained in comparisons of observed values and the values predicted by four ABL schemes for wind speed (WS), potential temperature $\left(T_{p}\right)$, and specific humidity $(q)$ for the period from 22 November 2008 at 00:00 UTC to 24 November 2008 at 18:00 UTC.

\begin{tabular}{|c|c|c|c|c|c|c|c|c|}
\hline & \multicolumn{2}{|c|}{ MRF-St } & \multicolumn{2}{|c|}{ MRF-Mod } & \multicolumn{2}{|c|}{ YSU-St } & \multicolumn{2}{|c|}{ YSU-Mod } \\
\hline & RMSE & BIAS & RMSE & BIAS & RMSE & BIAS & RMSE & BIAS \\
\hline WS $\left(\mathrm{m} \mathrm{s}^{-1}\right)$ & 2.46 & 2.25 & 2.56 & 2.38 & 2.91 & 2.85 & 2.80 & 2.75 \\
\hline$T_{p}(\mathrm{~K})$ & 1.75 & -0.31 & 1.97 & -0.43 & 2.16 & 0.90 & 2.22 & 0.39 \\
\hline$q\left(\mathrm{~g} \mathrm{~kg}^{-1}\right)$ & 1.13 & 0.95 & 1.16 & 0.99 & 0.96 & 0.81 & 1.03 & 0.88 \\
\hline
\end{tabular}

obtained using the MRF and YSU schemes were similar. The RMSE values for wind speed were between 2.46 and $2.91 \mathrm{~m} \mathrm{~s}^{-1}$ and were the highest for the YSU schemes. The mean values of wind speed, with a significance level of $95 \%$, were $5.0 \pm 0.3 \mathrm{~m} \mathrm{~s}^{-1}$ for MRF_St, $5.1 \pm 0.3 \mathrm{~m} \mathrm{~s}^{-1}$ for MRF_Mod, $5.4 \pm 0.2 \mathrm{~m} \mathrm{~s}^{-1}$ for YSU_St, and $5.3 \pm 0.2 \mathrm{~m} \mathrm{~s}^{-1}$ for YSU_Mod, respectively.

In the case of potential temperature, the predicted evolution was similar to the observed pattern, particularly with respect to the daily peak values. However, some differences were registered in the transition periods, for which the YSU parameterisations yielded higher values than did the MRF schemes. The range of RMSE values for the MRF schemes $(1.75-1.97 \mathrm{~K})$ was lower than that for the YSU schemes $(2.16-2.22 \mathrm{~K})$. A slight underestimation was generated by the MRF schemes $(-0.31,-0.43 \mathrm{~K})$ and a slight overestimation was generated by the YSU schemes $(0.39,0.90 \mathrm{~K})$. The mean values of potential temperature, with a significance level of $95 \%$, were $286.4 \pm 0.8 \mathrm{~K}$ for MRF_St, $286.2 \pm 0.7 \mathrm{~K}$ for MRF_Mod, $287.7 \pm 0.7 \mathrm{~K}$ for YSU_St, and $287.1 \pm 0.7 \mathrm{~K}$ for YSU_Mod, respectively.

The simulated results for specific humidity appropriately represented the observed temporal evolution of this parameter, and all four parameterisations yielded similar results. The simulations generally overestimated the observed values (a positive BIAS of 0.81 to $0.99 \mathrm{~g} \mathrm{~kg}^{-1}$ ), and the highest discrepancy was observed in the simulation of maximum daily values using the MRF schemes. Higher RMSE values were obtained for the MRF schemes $\left(1.16-1.13 \mathrm{~g} \mathrm{~kg}^{-1}\right)$ than for the YSU schemes $\left(1.03-0.96 \mathrm{~g} \mathrm{~kg}^{-1}\right)$. The mean values of specific humidity, with a significance level of $95 \%$, were $6.7 \pm$ $0.1 \mathrm{~g} \mathrm{~kg}^{-1}$ for MRF_St, $6.8 \pm 0.1 \mathrm{~g} \mathrm{~kg}^{-1}$ for MRF_Mod, 6.6 . $\pm 0.1 \mathrm{~g} \mathrm{~kg}^{-1}$ for YSU_St, and $6.7 \pm 0.1 \mathrm{~g} \mathrm{~kg}^{-1}$ for YSU_Mod, respectively.

Figure 5 compares the simulated potential temperature and specific humidity profiles for the fine grid domain (D4) with radiosonde observations recorded on 22 November at 16:00 UTC, 23 November at 13:00 UTC and 29 November at 16:00 UTC. The profiles modelled using all four ABL schemes were in good agreement concerning the definition of the convective layer. For the first two days, the temperature $(1-2 \mathrm{~K})$ was underestimated and the humidity $\left(1 \mathrm{~g} \mathrm{~kg}^{-1}\right)$ was overestimated, but for the third day, the simulations yielded slightly lower temperatures $(0.5-1 \mathrm{~K})$ and higher humidity values $\left(0.5 \mathrm{~g} \mathrm{~kg}^{-1}\right)$.

The mixing depth structures observed on the second and third days and the associated mixing layer heights (approximately $1100 \mathrm{~m} \mathrm{agl}$ and $1700 \mathrm{~m} \mathrm{agl}$, resp.) were well simulated by the model. However, for the first day, the simulation yielded a mixing layer height of $1600 \mathrm{magl}$ whereas with the empirical data indicated a stable layer. The simulated capping inversion obtained for each day ranged from relatively high values generated using the YSUSt scheme to lower values generated using the MRF-Mod scheme. The MRF-St, and YSU-Mod schemes yielded similar, intermediate height values.

As shown in Figure 5(d), all four ABL schemes generated similar patterns of temporal variation in ABL height over the analysed period. The predictions based on all four schemes were particularly similar for the first day; for the second and third days, the differences among them were more pronounced. The YSU-St scheme yielded the highest values across all three days, with values reaching almost $1800 \mathrm{~m}$ agl on 22 and 24 November and $1600 \mathrm{~m}$ agl on 23 November, and the lowest values (between 1200 and $1700 \mathrm{~m}$ agl) were generated by the MRF-Mod scheme. For 23 November, all parameterisations yielded similar patterns of variation from 08:00 to 17:00 UTC, but for 22 November and 24 November, progressive increases in the mixing depth beginning in the early morning hours were forecasted by the YSU schemes but not the MRF schemes.

The maximum differences between the model simulations of $\mathrm{ABL}$ height based on the four schemes were lower than $100 \mathrm{~m}$. The YSU-Mod and MRF-St predictions exhibited the strongest agreement with the observed ABL height for the first two days, whereas for the last day, the YSUSt and MRF-St schemes generated the best approximations to the observed mixing height.

\section{Discussion}

The comparative study presented here analysed the performance of four ABL parameterisations in the simulation of surface conditions under two contrasting meteorological scenarios. According to the statistical results (RMSE and BIAS), the degree of agreement between the observations and the model predictions was similar to that obtained in previous works $[29,30]$.

However, differences in the simulation results depending on the ABL schemes used were observed for both meteorological scenarios. In the case of potential temperature, the simulations displayed a statistical tendency to underestimate the observed values, similar to that observed in mesoscale meteorological models [31]. However, simulation results for the temporal evolution of potential temperature differed between models run using MRF schemes and those runs 

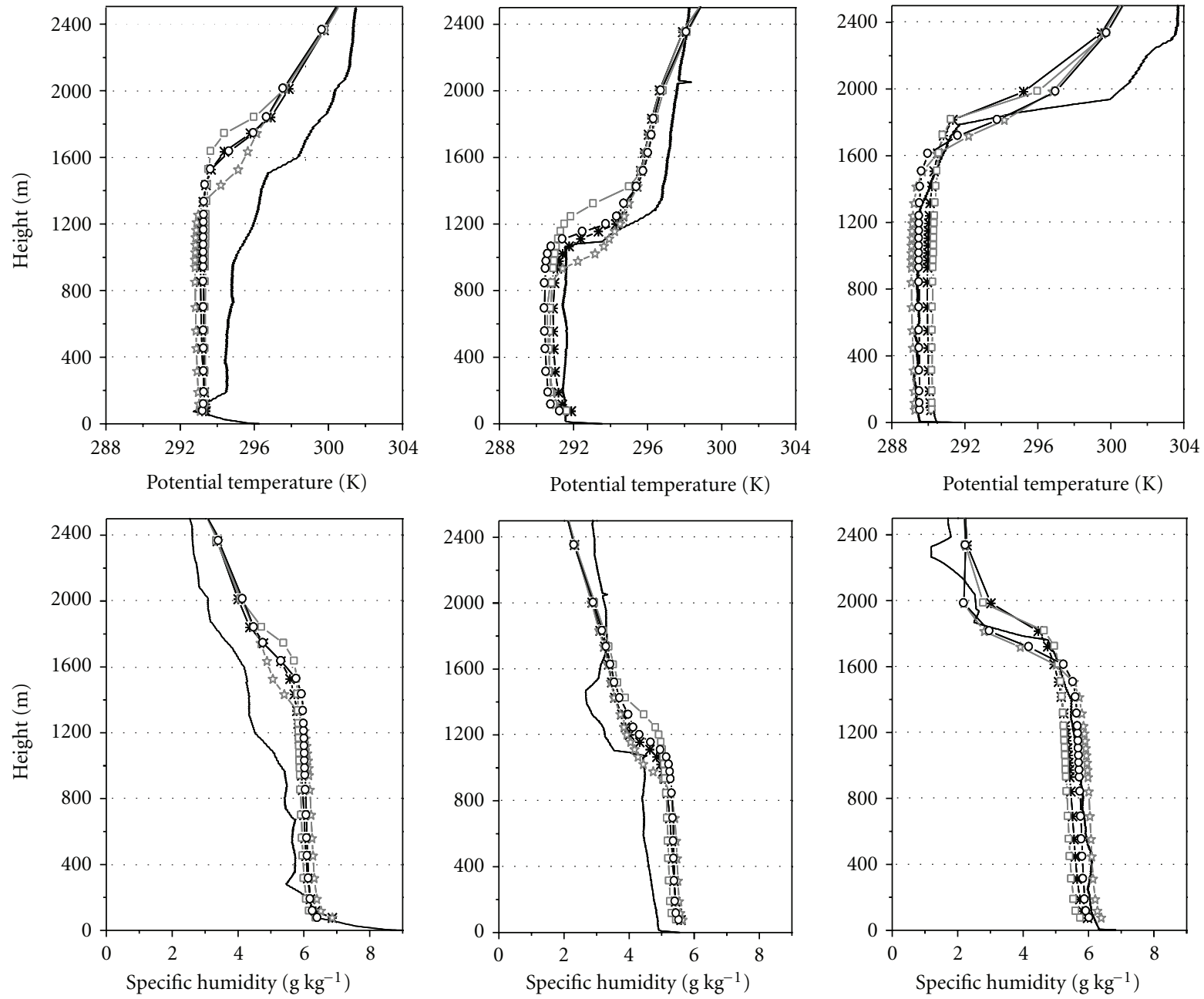

(a) $22 / 11 / 2011$ 16:00 UTC

(b) 23/11/2011 13:00 UTC

(c) $24 / 11 / 2011$ 16:00 UTC

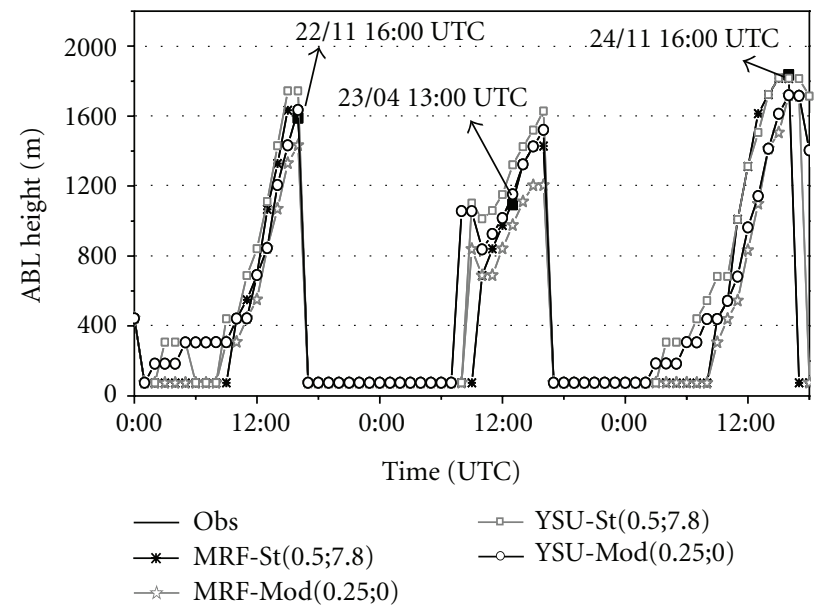

(d)

FIGURE 5: Vertical profiles of potential temperature and specific humidity based on observations (solid lines) and model simulations (lines + symbols) using the MRF-St, MRF-Mod, YSU-St, and YSU-Mod schemes for (a) 16:00 UTC on 22 November 2008, (b) 13:00 UTC on 23 November 2008, and (c) 16:00 UTC on 24 November 2008. (d) Hourly evolution of the mixing layer height obtained from the simulations (solid line) and from meteorological soundings (black points) for the period from 22 November 2008 at 00:00 UTC to 24 November 2008 at 18:00 UTC. 
using YSU schemes. The highest discrepancies were observed in the daily maximum values for the SW-NW flow scenario and in nighttime values for the NE flow scenario, but in both scenarios, the warmest values were obtained using the YSU schemes. For specific humidity, although similar values and patterns of evolution were obtained using both MRF and YSU schemes in each scenario, the YSU schemes generated lower maximum values in some cases.

Overall, then, the YSU schemes exhibited a tendency to generate higher temperature predictions and lower humidity predictions. This behaviour could be related to the impact that different meteorological conditions have on the ABL parameterisations. In this case, the flows analysed represent a maritime influence in the first case (wind from the SW-NW) and a continental influence in the second case (wind from the NE). The YSU schemes include an additional parameter to determine the thermal excess and produce larger values for the magnitude of the diffusion coefficients because the maximum value of $K$ is larger by a factor of 1.2 in the YSU PBL than in the MRF PBL.

In the case of wind speed, differences between the predictions generated using the different ABL schemes were found for both periods. Most notably, the YSU schemes registered higher variation in the surface wind speed than did the MRF schemes. This could be associated with differences in the formulation of the schemes, in particular, the fact that the YSU schemes use a nonlocal momentum transport in diurnal time whereas the MRF schemes use only local mixing. The results displayed a tendency to underestimate and overestimate the observed wind speeds in the SW-NW and NE flow scenarios, respectively. This difference could be related to the observed daily evolution of wind speed, as a well-marked daily cycle was observed for the SWNW flows and relatively homogeneous values were observed for the NE flows. The best approximation for the SWNW flow scenario was in agreement with [31], in which the optimal reproduction of the surface temperature was strongly correlated with a good approximation of the wind speed phase when the diurnal cycle of continental wind speed was approximately in phase with the thermal cycle [32]. These results were in contrast with those obtained by Steeneveld et al. [33], who found the largest differences between WRF-YSU and MRF results for nighttime during strong winds.

The results for the potential temperature and specific humidity profiles showed that both the MRF and YSU schemes appear to be optimal predictors of ABL structure. The two schemes generated similar thermal and humidity properties for the convective layer and logical differences in the determination of $\mathrm{ABL}$ height, although the maximum differences between the simulated and observed ABL heights ranged between 100 and $200 \mathrm{~m}$.

The MRF schemes produced a more stable boundary layer, whereas the YSU schemes generated a relatively wellmixed ABL structure. The simulations produced a cold bias of nearly $2 \mathrm{~K}$, and the simulated $\mathrm{ABL}$ tended to be drier in the SW-NW flow period and wetter in the NE flow period. These results are somewhat at odds with the results of the author in [34], who noted that the MRF and YSU schemes produce a dry and warm $\mathrm{ABL}$. In the current study, it was also observed that compared to the MRF-St scheme, the YSU-St scheme produced a colder surface layer in the early hours and a warmer surface layer in the later hours of the day, in agreement with [7].

The results also indicated that a reduction in the value of the $b$ coefficient resulted in lower simulated thermal properties. This is due to the influence of $b$ on the determination of excess surface temperature and the resulting effect of variation in this parameter on the potential temperature in the convective boundary layer. This result is in agreement with theoretical predictions [7] that enhanced $b$ coefficient values will increase the simulated temperatures in the convective boundary layer. In the current study, contrasting meteorological conditions did not influence this behaviour.

Differences between the ABL schemes were also observed in terms of the temperature near the inversion layer. The top of the ABL was slightly lower in the MRF simulations than in the YSU simulations, reflecting a difference in the formulation of the two schemes, and in particular, the inclusion of an explicit treatment of entrainment processes at the top of the ABL in the YSU scheme. Within this general trend, the predictions of the two schemes differed more under the arrival of NE flows than under the arrival of SW-NW flows. This could be related to the fact that relatively homogeneous thermal and humidity properties are associated with marine flows.

The simulated profiles indicated that modification of the value of $\mathrm{Rib}_{\mathrm{cr}}$ resulted in variation in the predicted ABL depth. Regardless of the parameterisation used, the simulated mixing height was higher for $\mathrm{Rib}_{\mathrm{cr}}=0.5$ than for $\operatorname{Rib}_{\mathrm{cr}}=0.25$. This is because a higher $\mathrm{Rib}_{\mathrm{cr}}$ value is associated with a greater degree of stability and the ABL height is incremented in this situation. This also means that when $\mathrm{Rib}_{\mathrm{cr}}$ is lower, the simulated profiles are colder and wetter compared to the empirical results in the convective boundary layer but warm and dry at the top due to an increase in the warm air at the top of the ABL. The removal of the countergradient term, indicated by $b=0$, generated a lower boundary layer depth, as was also observed in [9], because this term neutralises the gradient by cooling the lower portion of the $\mathrm{ABL}$ and warming the upper portion.

Regarding diurnal variation in the mixing height in response to daily variation in heat fluxes, both the YSU and MRF ABL schemes realistically simulated the growth and decay of the mixed layer. However, some temporal variation between the two schemes was observed. Although the YSU and MRF schemes simulated similar heights in the morning, the height simulated using the YSU scheme was higher than that simulated using the MRF scheme after midday. The YSU schemes also generated higher nighttime mixing heights, in agreement with the results of [7].

The analysis of diurnal variation in the mixing height indicated a further difference between the MRF and YSU parameterisations. When the mixing height was well defined, the ABL depth evolution obtained using the YSU parameterisation with $\mathrm{Rib}_{\mathrm{cr}}=0.25$ was similar to that obtained using the MRF scheme with $\mathrm{Rib}_{\mathrm{cr}}=0.5$. This result is consistent with that obtained by the authors of [7], who found that 
relative to the MRF scheme, the YSU scheme increases the height of the $\mathrm{ABL}$ when convection is generated by thermal processes and decreases this height when convection is induced by mechanical processes.

Taking into account this set of results, it is not easy to identify the most adequate parameterization scheme, because it depends on the analysed variable. Considering all the parameters analysed, the MRF ABL parameterisation with the lowest values of $\mathrm{Rib}_{\mathrm{cr}}$ and $b$ coefficients tested $(0.25$ and 0.0 , resp.) tends to show a realistic simulation. This configuration is similar to that used in [35], in which the WRF-ARW model was tested over the Iberian Peninsula using a Rib $\mathrm{cr}_{\mathrm{cr}}$ value of 0.3 .

\section{Conclusions}

The WRF-ARW model was used in this study to analyse the performance of different $\mathrm{ABL}$ parameterisation schemes in simulating surface meteorological conditions (wind direction and speed, potential temperature, and specific humidity) and ABL behaviour (structure and depth) over the southwestern coast of the Iberian Peninsula. The results of the four ABL schemes were compared with surface meteorological measurements and soundings during two contrasting periods of three days each in 2008, corresponding to the arrival of synoptic flows from the SW-NW and from the NE.

The performance of the standard MRF and YSU ABL parameterisations (MRF-St and YSU-St), each with a bulk critical Richardson number ( $\mathrm{Rib}_{\mathrm{cr}}$ ) of 0.5 and a coefficient of proportionality $(b)$ of 7.8 , was analysed. In addition, the forecasting results derived by decreasing the $\mathrm{Rib}_{\mathrm{cr}}$ to 0.25 and the $b$ coefficient to 0.0 in both parameterisations (MRF-Mod and YSU-Mod) were analysed. Both of these coefficients play key roles in the determination of ABL height, thermal properties, and humidity values by each of the ABL parameterisations.

The comparative analysis of the observed and predicted surface meteorological conditions revealed accurate simulation of wind direction behaviour by all four parameterisations as well as reliable representation of the observed evolution of potential temperature, specific humidity, and wind speed under both meteorological scenarios. Notably, in both periods, the YSU schemes registered the highest maximum thermal values and lower maximum values of specific humidity.

The results concerning the potential temperature and specific humidity profiles showed that both the MRF and YSU schemes appear to be optimal predictors of ABL structure. The two schemes generated similar thermal, and humidity properties for the convective layer and logical differences in the determination of ABL height, although the maximum differences between the simulated and observed $\mathrm{ABL}$ heights ranged between 100 and $200 \mathrm{~m}$. The simulations produced a cold bias of nearly $2 \mathrm{~K}$, and the simulated ABL tended to be drier in the SW-NW flow period and wetter in the NE flow period, with slight differences among the ABL schemes. The top of the PBL obtained using the MRF scheme was slightly lower than that obtained using the YSU scheme, reflecting the differences in the formulation of the schemes. In addition, the results indicated that modification of the value of $\mathrm{Rib}_{\mathrm{cr}}$ resulted in variation in the predicted ABL depth. Regardless of the parameterisation used, the simulated mixing height was higher for $\mathrm{Rib}_{\mathrm{cr}}=0.5$ than for $\operatorname{Rib}_{\text {cr }}=0.25$ because a higher Rib $\mathrm{br}_{\mathrm{cr}}$ value is associated with a greater degree of stability and an incremented ABL height.

Both the YSU and MRF schemes realistically simulated the growth and decay of the mixed layer. However, while all four parameterisations simulated similar heights in the morning, the height simulated using the YSU scheme was higher than that simulated using the MRF after midday. The YSU schemes also generated higher nighttime mixing heights.

Taking into account this set of results, it is not easy to identify the most adequate parameterization scheme, because it depends on the analysed variable. Considering all the parameters analysed, the MRF ABL parameterisation with the lowest values of $\mathrm{Rib}_{\mathrm{cr}}$ and $b$ coefficients tested (0.25 and 0.0, resp.) tends to show a realistic simulation. Due to this analysis which has been performed taking as reference only two synoptic scenarios over southwestern Iberian Peninsula, these results can serve as first reference data for further analyses that should be carried out to refine the modelling of the surface meteorological conditions and the ABL characteristics in this region. In addition, these results could be taken as example to apply WRF in a region similar to southwestern Iberian Peninsula.

\section{References}

[1] R. B. Stull, An Introduction to Boundary Layer Meteorology, Kluwer Academia Publishers, Dordrecht, The Netherlands, 1988.

[2] S. T. Rao, J.-Y. Ku, S. Berman, K. Zhang, and H. Mao, "Summertime characteristics of the atmospheric boundary layer and relationships to ozone levels over the Eastern United States," Pure and Applied Geophysics, vol. 160, no. 1-2, pp. 21$55,2003$.

[3] Q. Zhang and H. Li, "A study of the relationship between air pollutants and inversion in the ABL over the city of Lanzhou," Advances in Atmospheric Sciences, vol. 28, no. 4, pp. 879-886, 2011.

[4] S. Emeis, C. Münkel, S. Vogt, W. J. Müller, and K. Schäfer, "Atmospheric boundary-layer structure from simultaneous SODAR, RASS, and ceilometer measurements," Atmospheric Environment, vol. 38, no. 2, pp. 273-286, 2004.

[5] S. H. Franchito, V. Brahmananda Rao, T. O. Oda, and J. C. Conforte, "An observational study of the evolution of the atmospheric boundary-layer over Cabo Frio, Brazil," Annales Geophysicae, vol. 25, no. 8, pp. 1735-1744, 2007.

[6] A. M. Sempreviva, M. E. Schiano, S. Pensieri et al., "Observed development of the vertical structure of the marine boundary layer during the LASIE experiment in the Ligurian Sea," Annales Geophysicae, vol. 28, no. 1, pp. 17-25, 2010.

[7] S.-Y. Hong, Y. Noh, and J. Dudhia, "A new vertical diffusion package with an explicit treatment of entrainment processes," Monthly Weather Review, vol. 134, no. 9, pp. 2318-2341, 2006.

[8] Z. I. Janjic, "Nonsingular Implementation of the MellorYamada Level 2. 5 Scheme in the NCEP Meso model," NCEP Office Note 437, 2001. 
[9] S.-Y. Hong and H.-L. Pan, "Nonlocal boundary layer vertical diffusion in a medium-range forecast model," Monthly Weather Review, vol. 124, no. 10, pp. 2322-2339, 1996.

[10] J. S. P. Wisse and J. Vilà-Guerau de Arellano, "Analysis of the role of the planetary boundary layer schemes during a severe convective storm," Annales Geophysicae, vol. 22, no. 6, pp. 1861-1874, 2004.

[11] A. Dandou, M. Tombrou, K. Schäfer et al., "A comparison between modelled and measured mixing-layer height over Munich," Boundary-Layer Meteorology, vol. 131, no. 3, pp. 425-440, 2009.

[12] J. Dudhia, "Numerical study of convection observed during the Winter Monsoon Experiment using a mesoscale twodimensional model," Journal of the Atmospheric Sciences, vol. 46, no. 20, pp. 3077-3107, 1989.

[13] J. Dudhia, "A multilayer soil temperature model for MM5," Preprints, Sixth PSU/NCAR Mesoscale Model Users Workshop, Boulder, CO, PSU/NCAR, 1996.

[14] J. S. Kain and J. M. Fritsch, "A one-dimensional entraining/detraining plume model and its application in convective parameterization," Journal of the Atmospheric Sciences, vol. 47, no. 23, pp. 2784-2802, 1990.

[15] J. S. Kain and J. M. Fritsch, "Convective parameterisation for mesoscale models: the Kain-Fritsch scheme. The Representation of Cumulus Convection in Numerical Models," Meteorological Monographs, vol. 24, pp. 165-170, 1993.

[16] J. A. Adame, A. Lozano, J. P. Bolívar, B. A. De la Morena, J. Contreras, and F. Godoy, "Behavior, distribution and variability of surface ozone at an arid region in the south of Iberian Peninsula (Seville, Spain)," Chemosphere, vol. 70, no. 5, pp. 841-849, 2008.

[17] M. Sorribas, B. A. De La Morena, B. Wehner et al., "On the sub-micron aerosol size distribution in a coastal-rural site at El Arenosillo Station (SW-Spain)," Atmospheric Chemistry and Physics Discussions, vol. 11, no. 2, pp. 3813-3856, 2011.

[18] B. J. H. van Stratum, J. Vila-Guerau de Arellano, H. G. Ouwersloot, K. van den Dries, T. W. van Laar, M. Martinez et al., "Case study of the diurnal variability of chemically active species with respect to boundary layer dynamics during DOMINO," Atmospheric, Chemistry and Physics, vol. 12, pp. 5329-5341, 2012.

[19] J. Martín-Vide, Los Mapas Del Tiempo, Colección Geoambiente XXI, Davinci, Barcelona, Spain, 2005.

[20] W. C. Skamarock, J. B. Klemp, J. Dudhia et al., "A description of the Advanced Research WRF Version 2," NCAR Tech Notes 468+STR, 2005.

[21] N. B. Bliss and L. M. Olsen, "Development of a 30-arcsecond digital elevation model of South America," in Proceedings of the Pecora 13th Symposium, Human Interactions with the Environment: Perspectives from Space, Sioux Falls, South Dakota, Bethesda, Maryland, August 1996.

[22] J. R. Anderson, E. E. Hardy, J. T. Roach, and R. E. Witmer, "Land use and land cover classification system for use with remote sensor data," United States Geological Survey Professional Paper, no. 964, 1976.

[23] I. B. Troen and L. Mahrt, "A simple model of the atmospheric boundary layer; sensitivity to surface evaporation," BoundaryLayer Meteorology, vol. 37, no. 1-2, pp. 129-148, 1986.

[24] F. J. Marsik, K. W. Fischer, T. D. McDonald, and P. J. Samson, "Comparison of methods for estimating mixing height used during the 1992 Atlanta Field Intensive," Journal of Applied Meteorology, vol. 34, no. 8, pp. 1802-1814, 1995.

[25] D. H. P. Vogelezang and A. A. M. Holtslag, "Evaluation and model impacts of alternative boundary-layer height formulations," Boundary-Layer Meteorology, vol. 81, no. 3-4, pp. 245-269, 1996.

[26] P. Seibert, F. Beyrich, S. E. Gryning, S. Joffre, A. Rasmussen, and P. Tercier, "Review and intercomparison of operational methods for the determination of the mixing height," Atmospheric Environment, vol. 34, no. 7, pp. 1001-1027, 2000.

[27] A. A. M. Holtslag and Chin-Hoh Moeng, "Eddy diffusivity and countergradient transport in the convective atmospheric boundary layer," Journal of the Atmospheric Sciences, vol. 48, no. 14, pp. 1690-1698, 1991.

[28] P. S. Farrugia, J. L. Borg, and A. Micallef, "On the algorithms used to compute the standard deviation of wind direction," Journal of Applied Meteorology and Climatology, vol. 48, no. 10, pp. 2144-2151, 2009.

[29] V. S. Challa, J. Indracanti, M. K. Rabarison et al., "A simulation study of mesoscale coastal circulations in Mississippi Gulf coast," Atmospheric Research, vol. 91, no. 1, pp. 9-25, 2009.

[30] D. K. Papanastasiou, D. Melas, and I. Lissaridis, "Study of wind field under sea breeze conditions; an application of WRF model," Atmospheric Research, vol. 98, no. 1, pp. 102-117, 2010.

[31] D. L. Zhang and W. Z. Zheng, "Diurnal cycles of surface winds and temperatures as simulated by five boundary layer parameterizations," Journal of Applied Meteorology, vol. 43, no. 1, pp. 157-169, 2004.

[32] A. Dai and C. Deser, "Diurnal and semidiurnal variations in global surface wind and divergence fields," Journal of Geophysical Research D, vol. 104, no. 24, pp. 31109-31126, 1999.

[33] G. J. Steeneveld, L. F. Tolk, A. F. Moene, O. K. Hartogensis, W. Peters, and A. A. M. Holtslag, "Confronting the WRF and RAMS mesoscale models with innovative observations in the Netherlands: evaluating the boundary layer heat budget," Journal of Geophysical Research, vol. 116, Article ID D23114, 16 pages, 2011.

[34] J. E. Pleim, "A combined local and nonlocal closure model for the atmospheric boundary layer. Part II: application and evaluation in a mesoscale meteorological model," Journal of Applied Meteorology and Climatology, vol. 46, no. 9, pp. 13961409, 2007.

[35] R. Borge, V. Alexandrov, J. José del Vas, J. Lumbreras, and E. Rodríguez, "A comprehensive sensitivity analysis of the WRF model for air quality applications over the Iberian Peninsula," Atmospheric Environment, vol. 42, no. 37, pp. 8560-8574, 2008. 

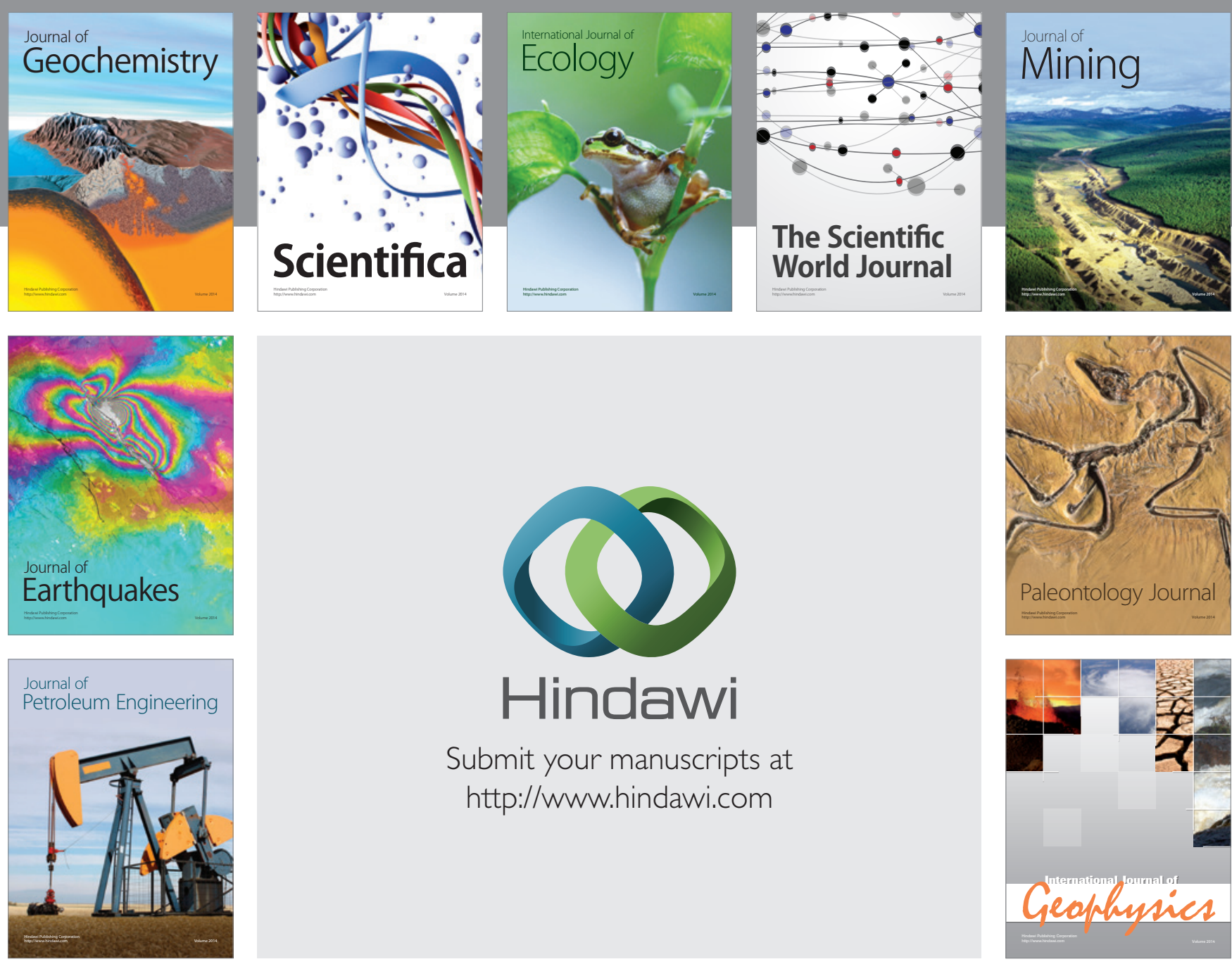

Submit your manuscripts at

http://www.hindawi.com
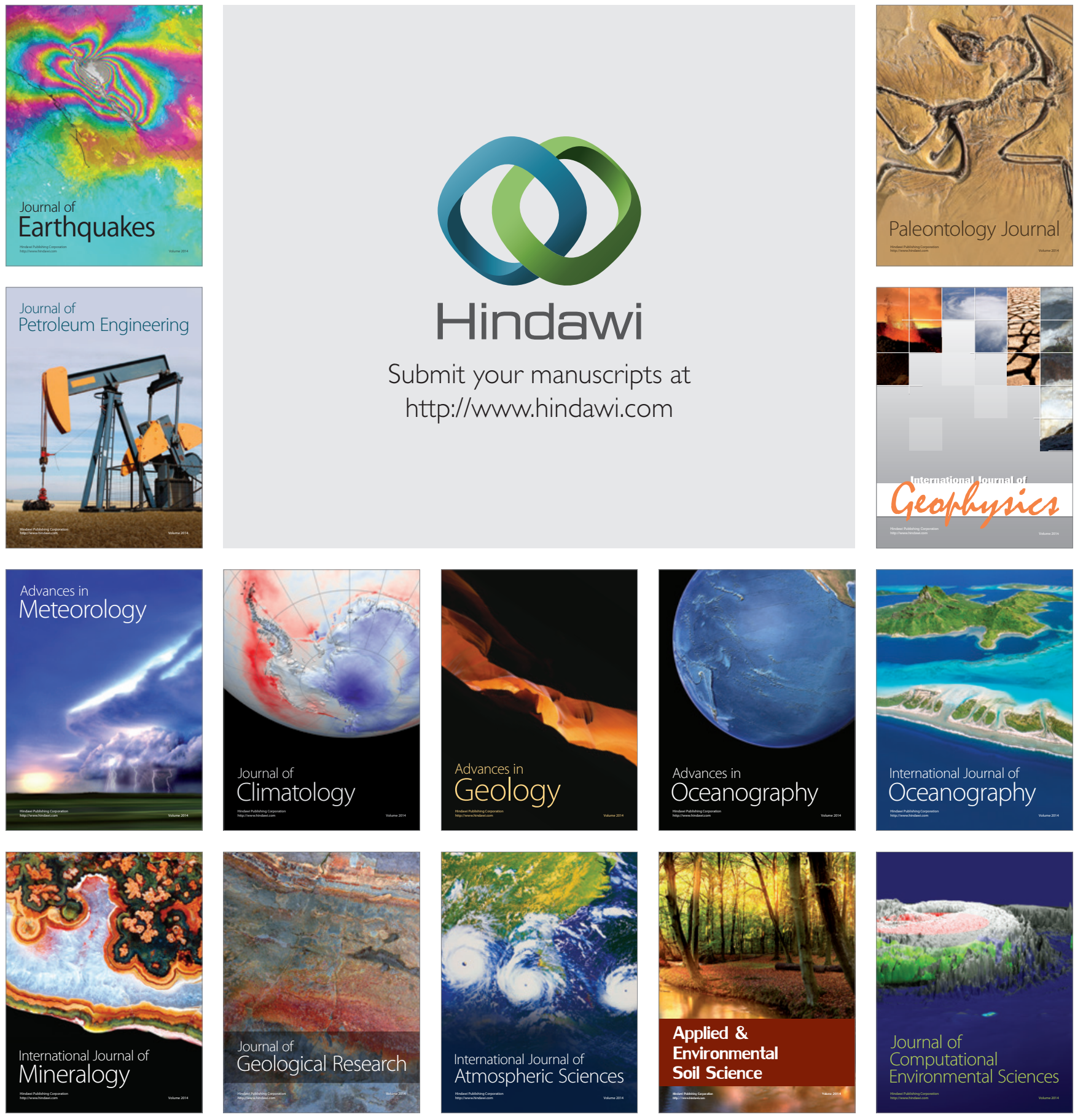